\title{
CARTOGRAFIA TEMÁTICA \\ Representaciones Cartográficas de Implantación Puntual y Lineal: Elaboración mediante Sistemas de Información Geográfica
}

\author{
Srta. Romina Claret \\ Srta. Carolina Cabrera \\ Prof. Liliana Ramírez \\ Facultad de Humanidades - UNNE
}

\section{RESUMEN}

La elaboración de Cartografía Temática, más específicamente la producción de representaciones cartográficas de implantación puntual y lineal, en términos tanto de procedimientos tradicionales como a través de Sistemas de Información Geográfica, es una labor cotidiana para aquellos profesionales que necesitan visualizar y hacer visualizar los fenómenos del mundo real sobre los cuales dan cuenta en sus estudios o abordajes temáticos. En este contexto, la presente contribución surge de la consulta y recopilación de información bibliográfica y digital y de la propia experiencia adquirida en circunstancias de tener que producir Cartografía Temática a partir de recursos informáticos. Por lo tanto la elaboración de este documento pretende inducir a la reflexión respecto de las fortalezas y debilidades o ventajas y desventajas que presentan los procesos de elaboración de Cartografía Temática que coexisten actualmente, a la vez que mostrar las potencialidades del subsistema de representaciones o salidas cartográficas incorporadas en los Sistemas de Información Geográfica.

\section{PALABRAS CLAVES}

Cartografía temática - Implantación puntal - Implantación lineal - Puntos por unidad - Símbolos proporcionales - Isolíneas - Isopletas.

\section{THEMATIC MAPPING \\ Cartographic Representations of Linear and Spot Implementation: It's Development Through Geographic Information Systems.}

\section{SUMMARY}

The development of Thematic Mapping, more specifically the production of cartographic representations of dot and linear implementation, both through traditional methods or Geographical Information Systems, is a daily work for those professionals who need to visualize and to make visible real world phenomena in which they base their studies or thematic approaches.

In this context, the present report is a result of bibliographic and website information search, as well as from the experiences of those who had already produced thematic mapping support for informatics resources.

Therefore this paper aims to encourage reflection about the strengths and weaknesses or advantages and disadvantages that manufacturing processes of thematic mapping represents, showing at the same time the potential of cartographic subsystems or layouts incorporated into GIS.

\section{KEY WORDS}

Thematic mapping - Spot implementation - Linear implementation - Dot density - Graduated symbols - Isoline - Isopleth. 


\section{INTRODUCCION}

La Cartografía Temática (en adelante CT) es una rama de la Cartografía, utilizada por numerosas ciencias para representar gráficamente fenómenos del espacio geográfico. En diversas fuentes se define a la CT como:

"Un ensayo geográfico que pretende reflejar las relaciones geográficas relativas a distribuciones particulares, se interesa por temas tales como densidades, magnitudes relativas, movimientos y diversos aspectos ambientales y geográficos de los fenómenos terrestres" (ROBINSON, 1987:33)

"Una cartografía especializada, destinada específicamente a la representación de cualquier elemento, proceso de actividad, con el énfasis puesto en la correcta identificación, caracterización, evaluación y representación del mismo" (OJEDA ZUJAR, 1999:1)

"Cartografía Temática es la que utilizando como soporte cartografía básica o derivada, singulariza o desarrolla algún aspecto concreto de la información adicional específica" (Ley de Ordenación de la Cartografía de España de 1986 -Ley № 7/1986 del 24 de enero, artículo 5-).

Según la Asociación Internacional de Cartografía "un mapa temático persigue el objetivo de evocar en la mente del receptor del mensaje cartográfico una imagen precisa y clara del ambiente espacial del fenómeno (ICA, 1993)". Par ello emplea diversas variables visuales o variables retinianas (forma, color, orientación, grano, valor y tamaño) que le permiten representar mediante objetos geométricos los fenómenos o entidades del mundo real. El empleo de estas variables visuales o retinianas se ajusta a dos aspectos significativos: el tipo de datos que se desee representar, es decir datos cuantitativos o cualitativos; y el tipo de implantación gráfica de los objetos geométricos, aspecto que depende de la escala de trabajo y define su implantación puntual, lineal o superficial. Respecto del primer aspecto, es decir el tipo de datos que se utiliza para la elaboración de la CT, en este aporte vamos a recortar la exposición al empleo de datos cuantitativos. En este sentido "los mapas cuantitativos son el resultado de la aplicación de ciencias cuánticas y experimentales, con el apoyo principalmente en la estadística descriptiva" (IGAC, 1993). Estos mapas generalmente representan datos que se miden en puntos o en áreas y muestran la localización, cuantificación y/o la distribución de los fenómenos sobre la superficie terrestre.

\section{REPRESENTACIONES CARTOGRÁFICAS CUANTITATIVAS DE IMPLANTACIÓN PUNTUAL: SÍMBOLOS PROPORCIONALES}

Fernand Joly define al "símbolo" como "la representación gráfica de un objeto o de un hecho en forma evocadora, simplificada o esquematizada sin implantación rigurosa" (Joly, 1979:85). Los símbolos proporcionales, que responden a la definición anterior, conforman una técnica que es muy utilizada en la ilustración de hechos del mundo real, debido a que permite representar valores absolutos asociados a puntos o superficies y valores relativos asociados a puntos o superficies. Así consideran a los hechos como entidades puntuales, aunque, a veces, posean una extensión superficial. Para el receptor presentan una clara visualización y una interpretación sencilla e intuitiva.

La elaboración de símbolos proporcionales consiste en una serie de pasos metodológicos que se inician con el análisis de la serie estadística a representar, la elección del mapa base y la selección de la figura geométrica a emplear - círculo, pentágono, hexágono, cuadrado, triángulo-, cuyo tamaño será ajustado en proporción a las cantidades que se quieran representar. La más empleada de las figuras geométricas es el círculo, debido a su forma compacta y de fácil construcción. Se los emplea para representar valores fundamentales o absolutos (ej.: la cantidad de habitantes, cantidad de industrias, cantidad de comercios), y valores derivados o relativos, como porcentajes, ratios, índices, tasas (ej.: porcentaje de población femenina analfabeta, tasa de mortalidad materna, porcentaje de industrias metalúrgicas). 
Tradicionalmente la elaboración de mapas cuantitativos de símbolos proporcionales se inicia con la labor de ordenar la serie estadística a representar y, para conocer la correspondencia entre el valor a representar y el tamaño de las figuras geométricas (en este caso el radio del círculo), es necesario calcular la raíz cuadrada de cada valor de la serie estadística. El resultado obtenido se puede utilizar en cualquier unidad de medida, siendo las más usuales los centímetros y milímetros. Si a pesar de ello, los radios de los círculos son excesivamente desmedidos en relación con el tamaño del mapa base elegido, los valores de los radios de toda la serie se pueden dividir por un número constante y la proporcionalidad se sigue manteniendo. Este proceso se acompaña con la elaboración de un gráfico denominado ábaco que permite visualizar el tamaño que adquieren las figuras geométricas a implantar en la representación. Concluida esta rutina, implantados los símbolos proporcionales en el mapa base, si la percepción visual no permitía dar cuenta de los contrastes cuantitativos que se presentan en la serie estadística, es preciso reiniciar el proceso. Esto puede suceder por dos motivos principales: a) la cantidad de intervalos de datos que se estableció no permite una clara diferenciación del comportamiento de la variable representada (figura 1); b) el tamaño de las figuras geométricas -máximas y mínimas- no permite una clara visualización del comportamiento de la variable representada (figura 2). En ambos casos el propósito final de una representación cartográfica que es la interpretación por parte del receptor será difícil de alcanzar.

El procedimiento señalado en el párrafo anterior, que en los procesos tradicionales de elaboración de cartografía podía implicar la ejecución del mismo en varias oportunidades, fue incorporado en las rutinas que permiten elaborar CT a través de los Sistemas de

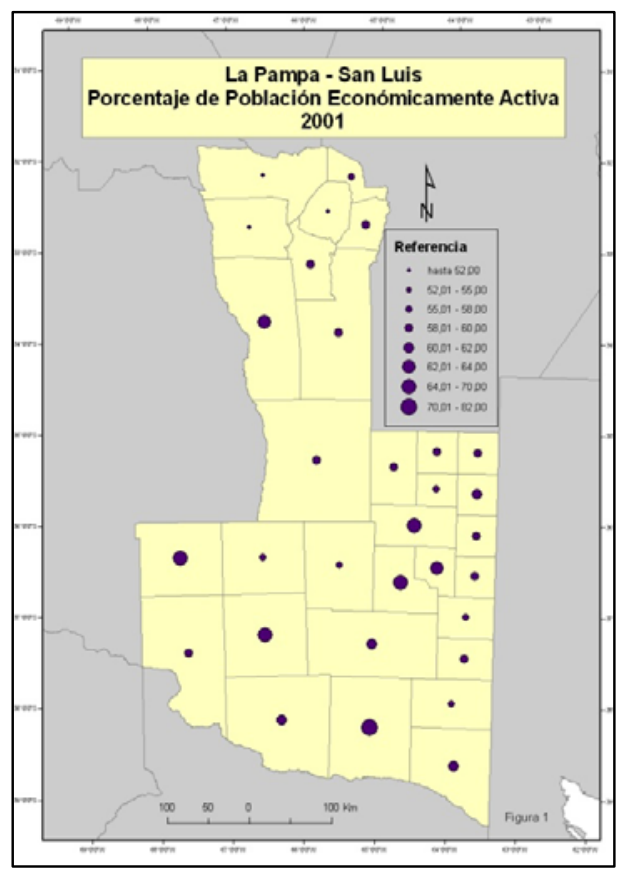
Información Geográfica (en adelante SIG), esta circunstancia determina que, en la actualidad, se puedan realizar múltiples operaciones en escaso tiempo y lograr de manera más ágil y prolija el mapa final más apropiado (figura 3). En este sentido podemos reforzar la idea de que la producción de documentos cartográficos mediante SIG tiene como fortaleza o como ventaja, la viabilidad que éstos
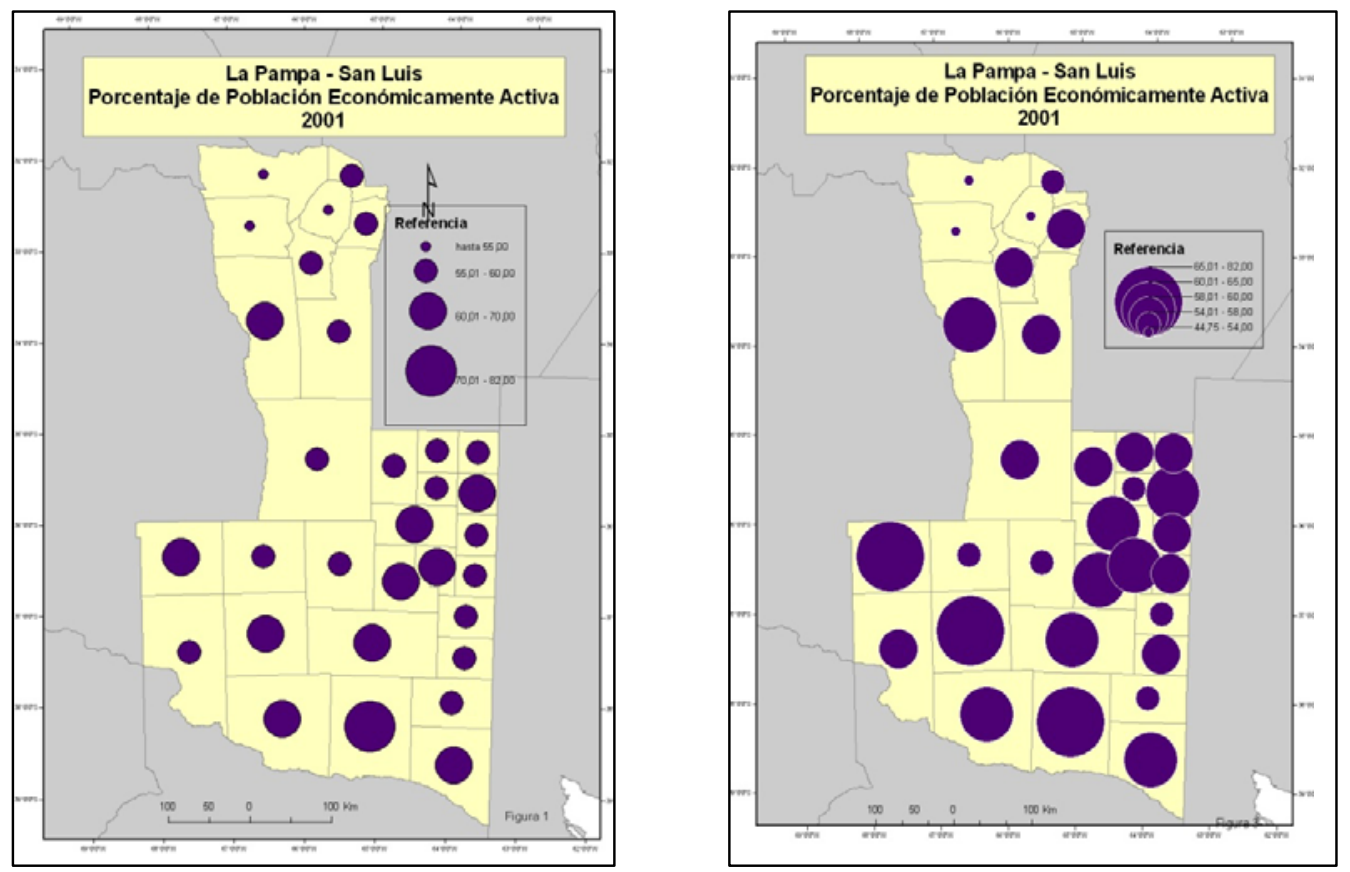

Publicado en formato digital: Prof. Romina Claret, Srta. Carolina Cabrera y Dra. Liliana Ramírez. CARTOGRAFIA TEMÁTICA. Representaciones Cartográficas de Implantación Puntual y Lineal: elaboración mediante Sistemas de Información Geográfica. Revista Geográfica Digital. IGUNNE. Facultad de Humanidades. UNNE. Año 7. № 14. Julio - Diciembre 2010. Resistencia, Chaco. En: http://hum.unne.edu.ar/revistas/geoweb/default.htm 
brindan para la generación de variados escenarios con una maniobra muy ágil de los datos, de los intervalos y de la simbología o semiología, permitiendo alcanzar un documento definitivo con mayores posibilidades de responder adecuadamente a las cualidades científicas y artísticas que requieren.

\section{REPRESENTACIONES CARTOGRÁFICAS CUANTITATIVAS DE IMPLANTACIÓN PUNTUAL: PUNTOS POR UNIDAD}

Los mapas cuantitativos de puntos graduados son documentos cartográficos que permiten mostrar la distribución de los valores absolutos que presentan determinados hechos sobre la superficie terrestre. Es un documento que combina la implantación gráfica puntual y superficial, ya que puede ser considerada una representación puntual debido a que los datos cuantitativos que ilustran se muestran a través de la repetición de puntos cuyo tamaño y valor son previamente determinados. No obstante, como la información estadística corresponde al valor que toman áreas o jurisdicciones en las que se mide el fenómeno, también puede ser considerada una representación de implantación areal que revela la distribución espacial del fenómeno del que pretende dar cuenta. Siempre se trabaja con valores absolutos, de esta manera cada punto representa un valor unitario, y se repiten hasta alcanzar el valor que tengamos que representar en el espacio geográfico con que se trabaje.

Así mismo, lo que parece tarea sencilla no lo es, pues deben tenerse en cuenta diversas cuestiones, tales como:

- Localización y distribución del punto: El punto representa la distribución del dato en un área (dominio territorial del punto) para lo que situaremos el punto según el principio del centro de gravedad o que significa generalización de la distribución. No obstante, la disposición de los puntos en el mapa puede responder a dos principios, pudiendo distribuirse de forma regular sobre el área o bien optar por una distribución más realista acorde a la presencia de factores geográficos, como ser la topografía, la presencia de cursos de agua, de desiertos o selvas. En el primer caso de distribución regular, la ubicación de los puntos está limitada a una unidad administrativa, careciendo de otras fuentes que ayuden a deducir localizaciones más concretas. Pero el principio que se ajusta más a la realidad es el de distribución en base a factores geográficos. En este caso, además de información numérica se dispone de información geográfica. Se llega así a detectar áreas en las que el dato, por razones lógicas, no pueda aparecer
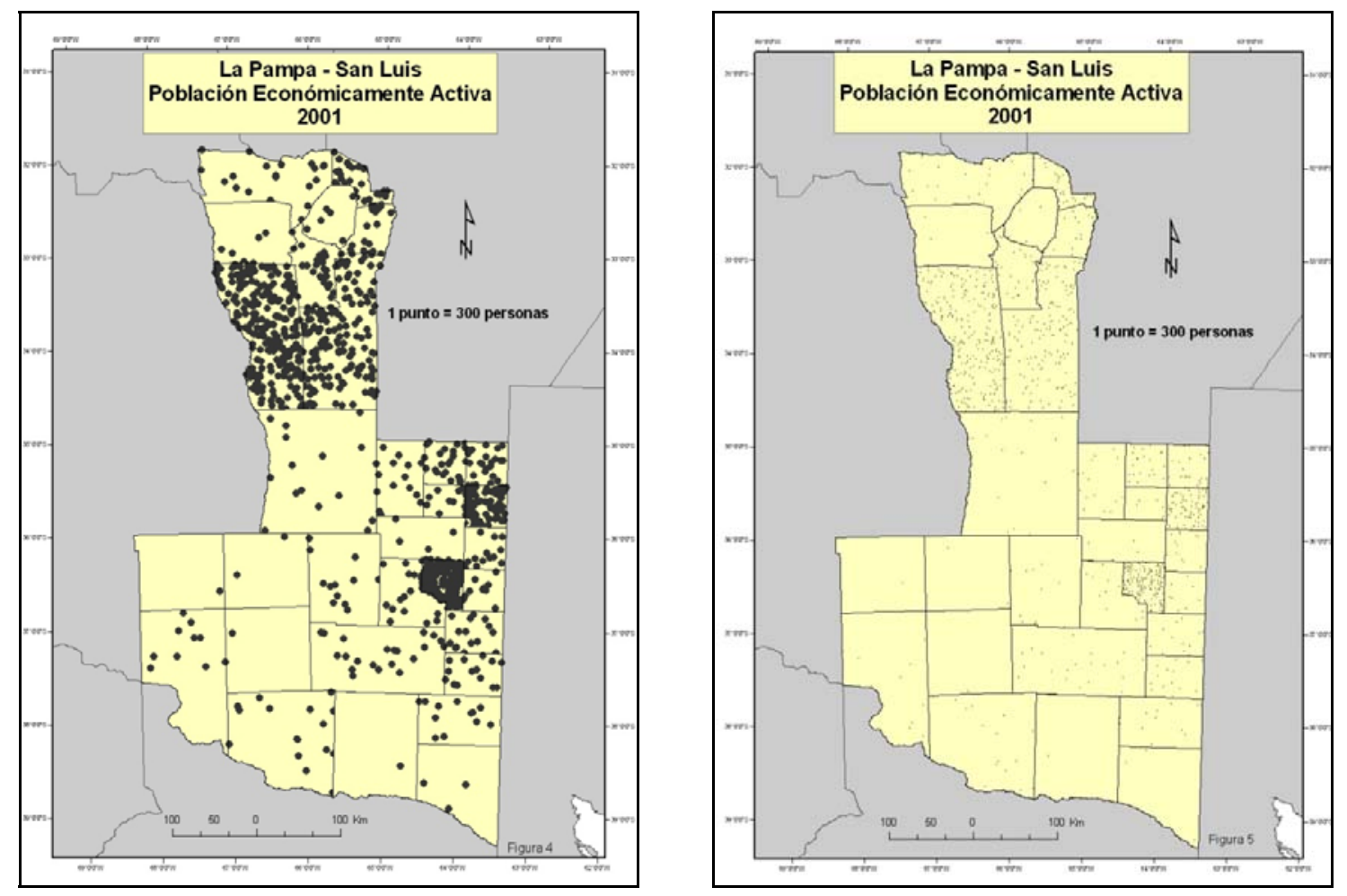

Publicado en formato digital: Prof. Romina Claret, Srta. Carolina Cabrera y Dra. Liliana Ramírez. CARTOGRAFIA TEMÁTICA. Representaciones Cartográficas de Implantación Puntual y Lineal: elaboración mediante Sistemas de Información Geográfica. Revista Geográfica Digital. IGUNNE. Facultad de Humanidades. UNNE. Año 7. № 14. Julio - Diciembre 2010. Resistencia, Chaco. En: http://hum.unne.edu.ar/revistas/geoweb/default.htm 
- Tamaño del punto: La dimensión del punto también es un aspecto relevante que se debe estimar y en muchas ocasiones es preciso experimentar en varias ocasiones para alcanzar el tamaño adecuado, ya que de lo contrario es posible caer en errores, tales como el que se muestra en la figura 4 cuando el tamaño que se le asigna al punto es muy grande, abarca mucha superficie y entorpece la correcta interpretación; o en la figura 5 en donde el tamaño elegido ha sido demasiado pequeño y, al igual que en el caso anterior, no permite al receptor interpretar de manera apropiada el contenido del mapa temático.
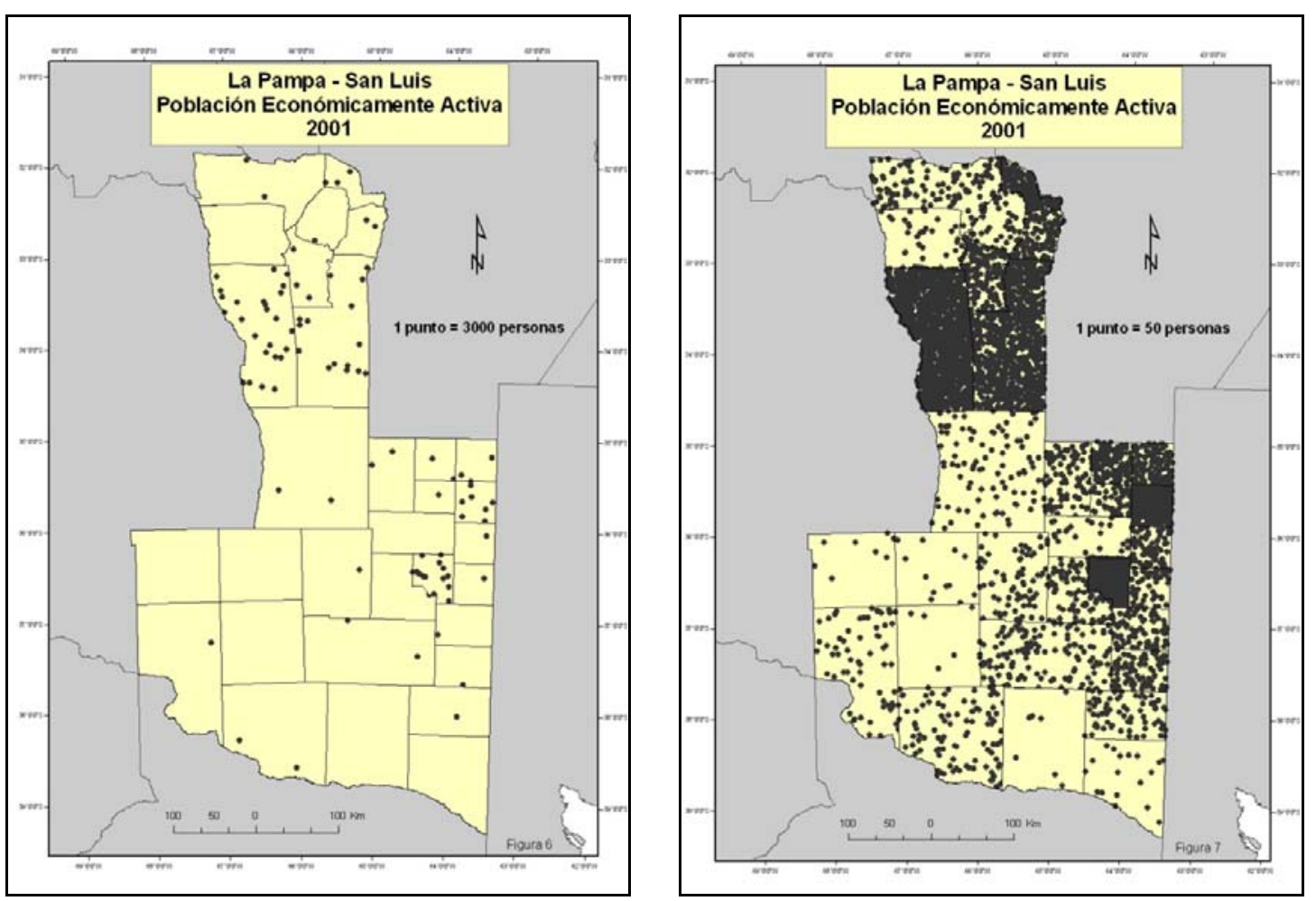

Publicado en formato digital: Prof. Romina Claret, Srta. Carolina Cabrera y Dra. Liliana Ramírez. CARTOGRAFIA TEMÁTICA. Representaciones Cartográficas de Implantación Puntual y Lineal: elaboración mediante Sistemas de Información Geográfica. Revista Geográfica Digital. IGUNNE. Facultad de Humanidades. UNNE. Año 7. № 14. Julio - Diciembre 2010. Resistencia, Chaco. En: http://hum.unne.edu.ar/revistas/geoweb/default.htm 
Valor del punto: esta peculiaridad es tan significativa como las dos anteriores. La figura 6 refleja que, si el valor que se le asigna a un punto es muy alto, en el mapa aparecerán pocos puntos, dificultando la posibilidad de plasmar una adecuada distribución de la variable. Por el contrario en la figura 7 , cuando el punto representa un número demasiado bajo, la cantidad de puntos necesarios para representar el valor en cuestión puede llegar a abarcar toda la superficie cartografiada. En ambos casos se estaría perjudicando la percepción visual e interpretación de la representación cartográfica.

Por lo expuesto, la elaboración de estos mapas de puntos o mapas de puntos graduados requieren de numerosos intentos de preparación para llegar al documento definitivo, y en esta instancia los SIG son merecedores de una alta potencialidad destinada a ensayar en una multiplicidad de ocasiones la misma cartografía, valorar los resultado y seleccionar aquella que reúne las mejores condiciones de cara al objetivo originalmente planteado. Así la figura 8 contiene la representación que, desde nuestra mirada, es la que alcanza las cualidades más convenientes, ya que un adecuado tamaño y valor logran

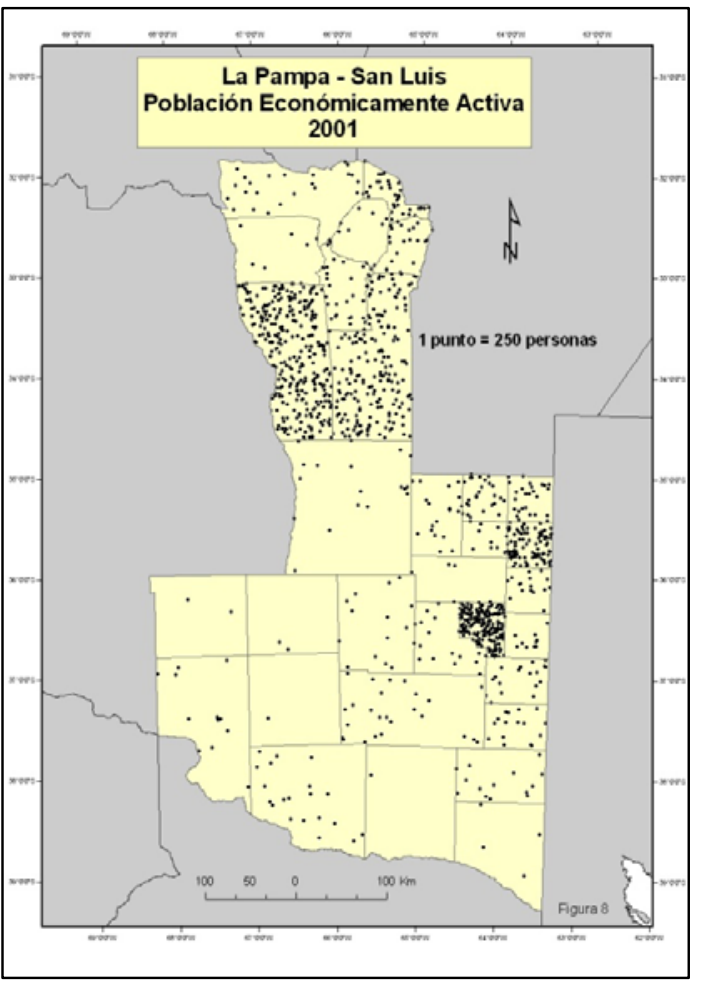
reflejar mejor la distribución de la variable representada.

\section{REPRESENTACIONES CARTOGRÁFICAS CUANTITATIVAS DE IMPLANTACIÓN LINEAL: MAPAS DE ISOLINEAS}

Para la Real Academia de la Lengua Española (1995), el prefijo iso "significa igualdad o denota uniformidad o semejanza". Es este sentido, las isolíneas son líneas que unen puntos de igual valor (figura 9). Los datos representan la unión de puntos que provienen de mediciones y en base a ellos se procede a interpolarlos a fin de determinar "valores no conocidos a partir de valores conocidos" (Barrera, 1999).

En un intento por sintetizar las características

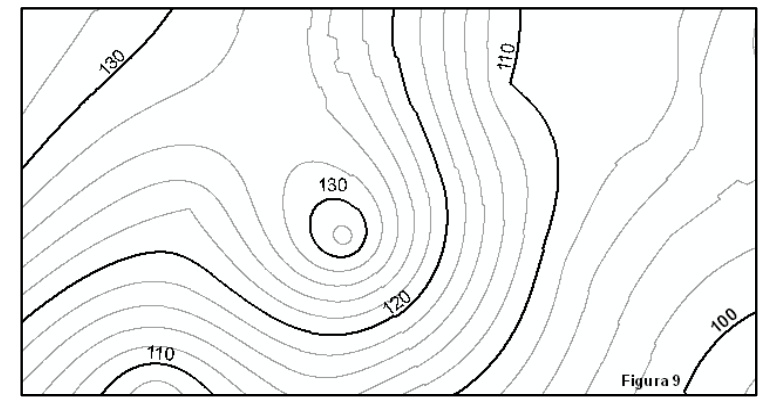
de las isolíneas, a continuación se señalan las particularidades más significativas:

- Todas las isolíneas se cierran, a pesar de que los mapas no las muestren de manera completa, se asume que la distribución del fenómeno que representan es continua y no puede desaparecer de manera brusca.

- No es posible que las isolíneas se crucen puesto que cada una representa un único valor.

- El acercamiento o la separación entre las isolíneas, muestra las características de la variación del fenómeno en relación con la distancia. Cuando estas se acercan expresan un cambio notorio del fenómeno y cuando se separan el cambio es gradual, más suave o lento.

- En relación con este último aspecto, el gradiente permite determinar cuál es el grado de variación del fenómeno, presentando una relación de cambio en función de aspectos tales como la distancia, el tiempo y la velocidad. Por ejemplo, en el gradiente bárico, como lo expresa Monkhouse, "un gradiente pronunciado implica una gran diferencia de presión con isobaras muy próximas, mientras que un gradiente débil implica solo una 
pequeña diferencia con isobaras muy distantes". Así mismo es conveniente pensar en otros aspectos asociados al fenómeno; siguiendo al mismo autor "un gradiente pronunciado suele estar asociado a fuertes vientos" (Monkhouse, F. and Wilkinson $\mathrm{H}$, 1966)

- La técnica de isolíneas es una de las más importantes en el cartografiado cuantitativo, y es la que junto con los mapas de isopletas y coropletas proporciona buena parte del volumen de mapas temáticos cuantitativos que se producen.

Los mapas de isolíneas se emplean para proporcionar una visión global de la configuración de la superficie estadística, para mostrar la variación espacial de un fenómeno en el espacio y para representar la localización de una serie de cantidades. Por otro lado se adapta fácilmente a distintos niveles de precisión y detalles, por lo que podemos considerarlo un sistema flexible, y la obtención de este tipo de mapa por medios automáticos, como por ejemplo los SIG, es en la actualidad una labor relativamente sencilla.

Numerosos fenómenos que se presentan en el territorio son medidos en puntos y, como consecuencia, es posible representar su disposición a través del empleo de isolíneas; a continuación, sin ánimo de ser exhaustivos, se presentan algunos ejemplos, tomados de Madrid, A. y Ortíz, L.

\section{DENOMINACIÓN}

\begin{tabular}{|c|c|}
\hline Isohipsas & $\begin{array}{l}\text { Líneas que unen valores de la misma altura, también llamadas curvas de } \\
\text { nivel. Probablemente son las isolíneas más conocidas y utilizadas cuya } \\
\text { información es la base para la elaboración de otras isolíneas }\end{array}$ \\
\hline Isobatas & $\begin{array}{l}\text { Líneas que unen puntos de igual profundidad en el mar. Se utilizan para } \\
\text { identificar la diferencia altitudinal de la topografía marina }\end{array}$ \\
\hline $\begin{array}{l}\text { Isoclinas/ } \\
\text { Isotracónicas }\end{array}$ & Líneas que unen puntos con la misma pendiente \\
\hline Isocapa & Líneas que unen puntos de igual altitud de un estrato geológico \\
\hline Isogonas & $\begin{array}{l}\text { Líneas que unen puntos con la misma declinación con relación al polo } \\
\text { magnético }\end{array}$ \\
\hline Isopaca & $\begin{array}{l}\text { Líneas que unen puntos de igual potencia de una determinada formación } \\
\text { geológica }\end{array}$ \\
\hline Isoyetas o Isohietas & Líneas que unen puntos de igual pluviometría \\
\hline Isogeoterma & $\begin{array}{l}\text { Líneas que unen puntos de igual temperatura de las profundidades de un } \\
\text { determinado astro o planeta }\end{array}$ \\
\hline Isotermas & Líneas que unen puntos de igual temperatura \\
\hline Isohelias & Líneas que unen puntos con la misma incidencia de brillo solar \\
\hline Isobaras & $\begin{array}{l}\text { Líneas que unen puntos que presentan la misma presión atmosférica. } \\
\text { Según Monkhouse y Wilkinson (1978) también se les denomina isalóbara o } \\
\text { isanomala }\end{array}$ \\
\hline Termoisoalinas & $\begin{array}{l}\text { Líneas que unen puntos de igual temperatura con relación a la profundidad } \\
\text { del lecho marino. }\end{array}$ \\
\hline Isobrontias & $\begin{array}{l}\text { Líneas que unen lugares en los que se registran tormentas en un mismo } \\
\text { momento. }\end{array}$ \\
\hline Isoqueimas & Líneas que unen puntos de igual de temperatura en invierno \\
\hline $\begin{array}{l}\text { Isotalantósicas/ } \\
\text { Isotalantas }\end{array}$ & Líneas que unen puntos que registran igual amplitud térmica anual \\
\hline
\end{tabular}




\begin{tabular}{|c|c|}
\hline Isocrimas & Líneas que representan los períodos de tiempo más fríos \\
\hline Isocinéticas & Líneas que unen puntos con la misma velocidad de viento \\
\hline Isonefas & Líneas que unen puntos con el mismo nivel de precipitación de nieve \\
\hline Isanémona & Líneas que unen puntos de igual velocidad mediana del viento \\
\hline Isanómala & $\begin{array}{l}\text { Líneas que unen puntos de igual anomalías de un elemento o fenómeno } \\
\text { especialmente meteorológico }\end{array}$ \\
\hline Isoamplitud & Líneas que unen puntos de igual oscilación térmica yo amplitud \\
\hline Isocasma & Líneas que unen puntos de igual frecuencia anual de visibilidad de auroras \\
\hline Isomera & $\begin{array}{l}\text { Líneas que unen puntos de igual porcentaje de precipitaciones mensuales } \\
\text { o estacionales con respecto al total anual }\end{array}$ \\
\hline $\begin{array}{l}\text { Isolíneas de } \\
\text { escorrentía } \\
\text { superficial }\end{array}$ & Líneas que unen puntos de igual cantidad de flujo de agua en superficie \\
\hline $\begin{array}{l}\text { Isolíneas de } \\
\text { caudales }\end{array}$ & Líneas que unen puntos de igual variación en el caudal de un río \\
\hline Isohalina & $\begin{array}{l}\text { Líneas que unen puntos de igual salinidad del agua tanto en el sentido } \\
\text { vertical como en el horizontal }\end{array}$ \\
\hline Isoiketas & $\begin{array}{l}\text { Líneas que unen puntos de igual grado de habitabilidad de especies } \\
\text { animales y vegetales }\end{array}$ \\
\hline Isofitas & Líneas que unen puntos de igual crecimiento vegetativo \\
\hline $\begin{array}{l}\text { Isolíneas de } \\
\text { evaporación }\end{array}$ & Líneas que unen puntos de igual cantidad de vapor de agua en el aire \\
\hline $\begin{array}{l}\text { Isolíneas de } \\
\text { inundación }\end{array}$ & Líneas que unen puntos de igual avance de las corrientes hídricas \\
\hline $\begin{array}{l}\text { Isolíneas de } \\
\text { contaminación }\end{array}$ & Líneas que unen puntos de igual cantidad de partículas contaminantes \\
\hline Isosísmicas & Líneas que unen puntos de igual intensidad de los sismos \\
\hline Isodemas & Líneas que unen puntos de igual densidad o cantidad poblacional \\
\hline Isoprecios & $\begin{array}{l}\text { Líneas que unen puntos de igual valor monetario. Se utiliza para señalar el } \\
\text { precio o la renta de la tierra }\end{array}$ \\
\hline Isodapanas & $\begin{array}{l}\text { Líneas que unen puntos de igual coste total del transporte en la teoría de la } \\
\text { localización industrial }\end{array}$ \\
\hline Isofora & $\begin{array}{l}\text { Líneas que unen puntos de igual tarifas del transporte a partir de un centro } \\
\text { determinado }\end{array}$ \\
\hline Isocronas & Líneas que unen puntos de igual tiempo o regularidad horaria \\
\hline $\begin{array}{l}\text { Isolíneas de } \\
\text { criminalidad }\end{array}$ & Líneas que unen puntos de igual nivel de criminalidad (robos, asesinatos) \\
\hline
\end{tabular}

En los mapas cuantitativos de isolíneas, a partir de la distribución de puntos en la superficie, cuyos valores son conocidos, se estiman los valores no conocidos y luego se procede al trazado de las líneas que unen valores análogos. La "estimación" de los valores se realiza a través de los procesos de "interpolación"; este procedimiento, que en la cartografía tradicional significaba una labor tediosa y sumamente prolongada, ha sido incluido en las funcionalidades de los SIG de una forma muy satisfactoria, incluyéndose variadas formas de interpolar puntos que luego derivan en mapas de superficies y también en modelos digitales de terreno como veremos en el próximo apartado. Entre los métodos de interpolación podemos citas: kriging (figura 10), IDW o interpolación ponderada por la distancia (figura 11), spline, quiebres naturales, regresión polinomial, shepard, mínima curvatura, funciones radiales, entre otras. 


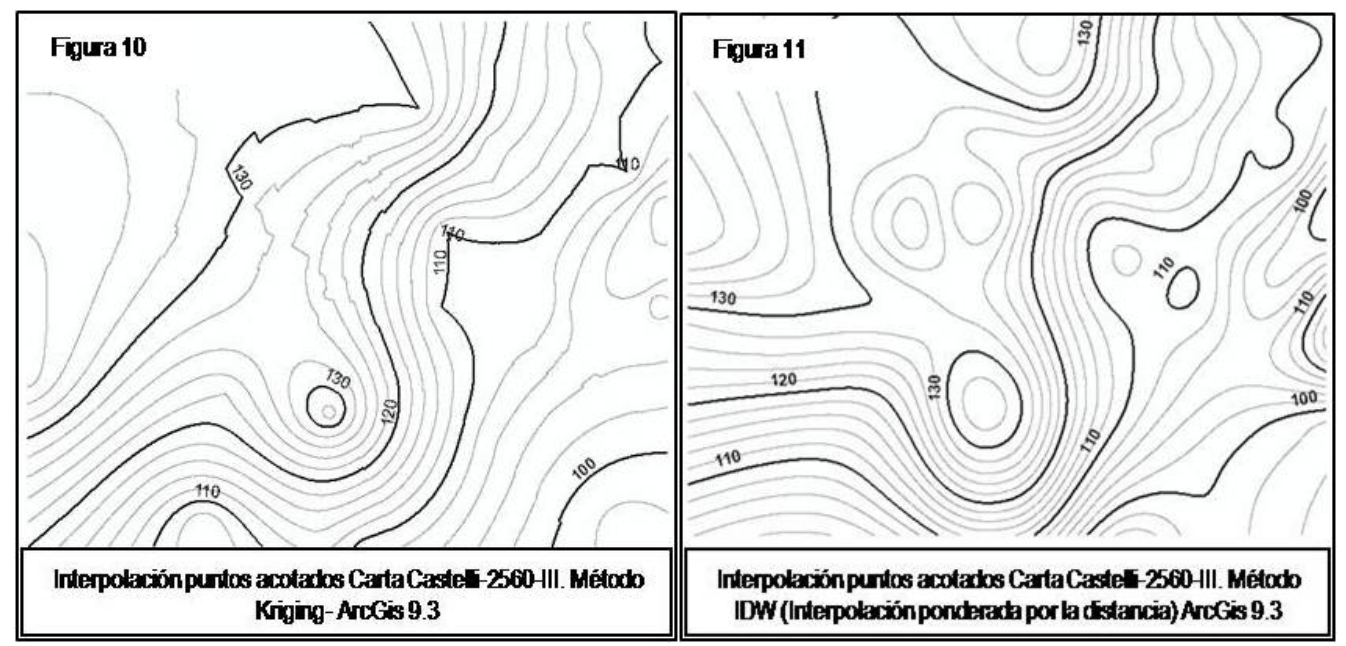

Como vemos en las figuras anteriores los diferentes métodos de interpolación arrojan disímiles resultados y ello permite que se puedan experimentar distintos escenarios hasta alcanzar aquel que se considera más adecuado, creemos que esta posibilidad determina una alta versatilidad que redunda en beneficios para el proceso de elaboración de CT.

\section{REPRESENTACIONES CARTOGRÁFICAS CUANTITATIVAS DE IMPLANTACIÓN LINEAL: MAPAS DE ISOPLETAS}

Cuando se cuenta con una serie estadística que contiene datos que han sido medidos en superficies tales como unidades administrativas o jurisdicciones (ej. densidades, tasas, índices, porcentajes), es posible asignar esos valores a puntos de control que se correspondan con cada una de las unidades espaciales; así, una vez definida la distribución de los puntos, se procede a interpolarlos de forma análoga a lo señalado en el apartado anterior. Tras este procedimiento surgen las "isopletas" que se definen como líneas que unen áreas de igual valor, la diferencia sustancial con las isolíneas es que luego de la generación de éstas se aplica un sombreado, grisado, color degradado o color en gradación a fin de mostrar de forma más evidente los cambios cuantitativos en superficie. Esta etapa en el proceso de elaboración de CT es una prolongación del trazado de isolíneas y, se podría decir, que todas las isolíneas señaladas en el cuadro anterior pueden convertirse en isopletas. Finalmente, a partir del delineado de las isopletas podemos obtener modelos digitales de terreno (MDT); este tipo de representación es aplicable a cualquier variable mensurable que dé cuenta de hechos que acontecen sobre la superficie terrestre, en este caso la visualización en tres dimensiones suele mostrar de forma más eficaz los variabilidades en superficie.

En virtud de todo lo expuesto el proceso completo sería como se muestra en la secuencia de figuras $12,13,14$ y $15 a$ y $15 b$, en las cuales se parte de los puntos de control referidos, en este caso, a las cotas de la Carta Castelli-2560-III, en escala 1:250.000 y se generan las isolíneas, las isopletas y dos ejemplos de MDT, que en este caso particular son Modelos Digitales de Elevaciones ya que se refieren a altura del terreno. 


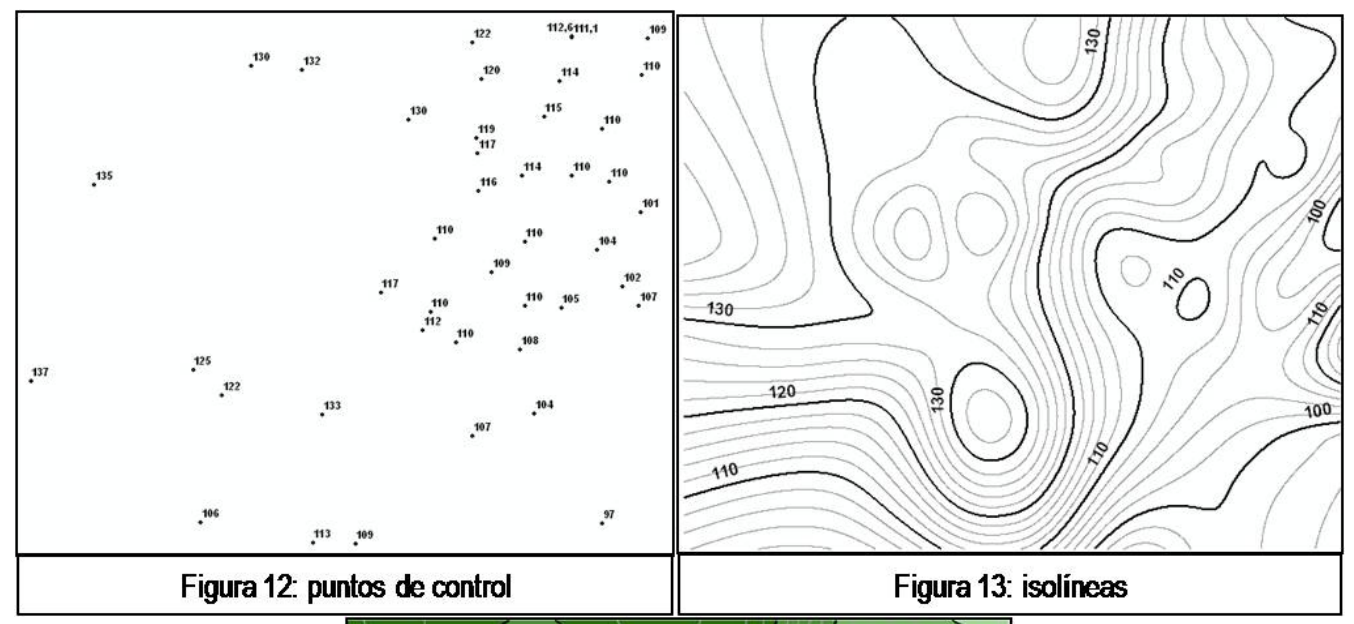

\section{Figura 12. puntos de control}

\section{Figura 13: isolineas}

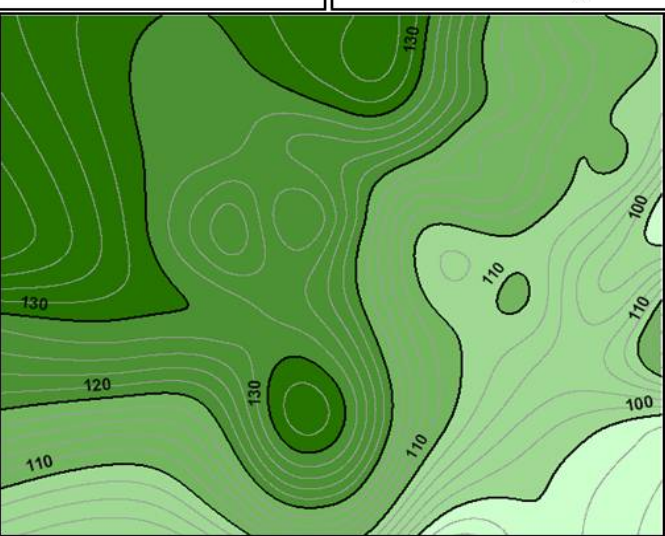

Figura 14: isopletas

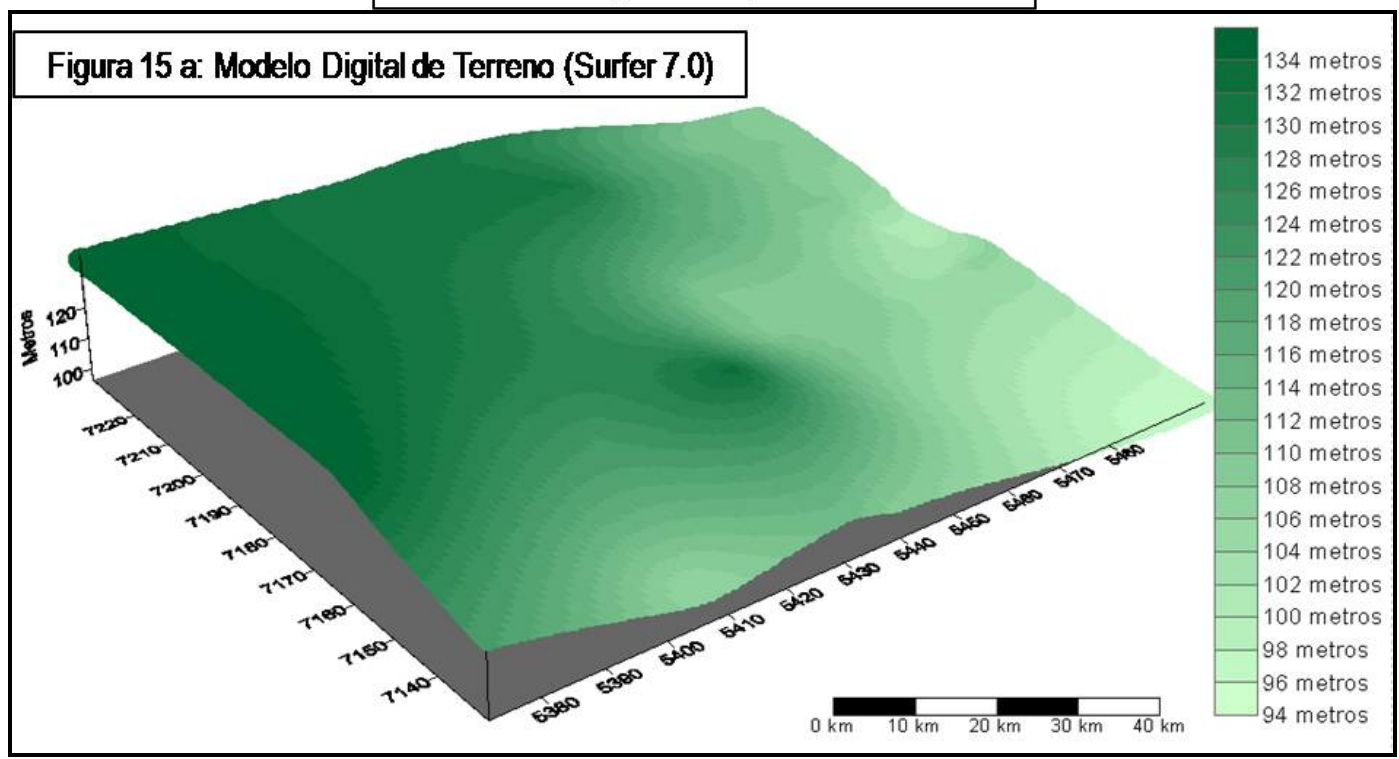




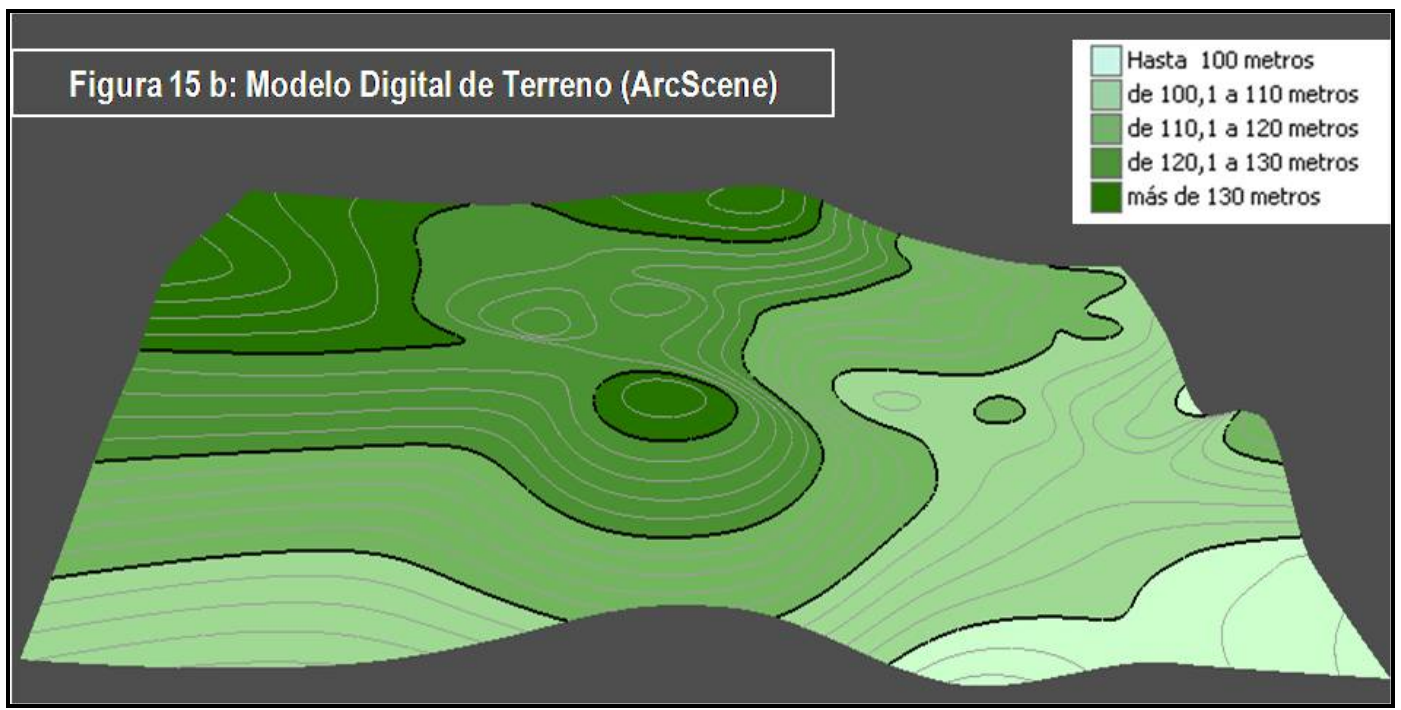

\section{CONSIDERACIONES FINALES}

La Cartografía Temática es de gran utilidad para el geógrafo y para todos los especialistas que desean comprender ciertos aspectos de un determinado espacio geográfico, ya que el propósito que persigue, al igual que la ciencia cartográfica en general, es representar, valiéndose de procesos manuales o computarizados, que involucran cuestiones científicas, técnicas y artísticas, las entidades que conforman el mundo real es decir los fenómenos y los hechos que se estudian e investigan en las diferentes Ciencias de la Tierra.

La elección de la representación cartográfica que mejor simbolizará el mundo real y la/s técnica/s que demanda/n su elaboración es uno de los momentos más relevantes en el proceso de elaboración ya que de él depende que el mensaje a transmitir sea decodificado exitosamente por el lector del mapa.

En la actualidad, la labor cartográfica tradicional es reemplazada, cada vez más, por el empleo de los Sistemas de Información Geográfica ya que, entre otras cuestiones, permiten realizar la tarea más rápida y prolija. No obstante se deben tener las mismas consideraciones que con la cartografía tradicional, ya que de ello permitirá cumplir con el objetivo que persigue la representación cartográfica. Los SIG son un recurso muy potente que integran información geográfica y tienen como finalidad principal encontrar soluciones a problemas muy diversos. No obstante los SIG's desempeñan un papel fundamental en la representación de la información geográfica, debido a que poseen funcionalidades que permiten alcanzar satisfactoriamente las cualidades científicas y artísticas que requiere cualquier documento cartográfico.

El permanente avance que experimenta la elaboración de cartografía mediante los SIG requiere, por parte del geógrafo, de una continua capacitación en el manejo de los mismos. Se trata de un recurso que facilita mucho la labor cartográfica pero se la debe enriquecer con el accionar crítico. Más allá de lo laborioso que llega a ser la cartografía tradicional, de ésta se incorpora el hábito de poner especial atención en los detalles. La estética y la percepción visual son requisitos de suma importancia para que la representación cumpla con el propósito perseguido, y ello no queda garantizado con el simple hecho de aplicar un SIG, sino que sigue siendo substancial la capacidad de evaluación y valoración reflexiva y crítica sobre la elaboración cartográfica, analizando, permanentemente, la producción que devuelve un SIG.

\section{BIBLIOGRAFIA}

BARRERA, S. (1999). "5. Diseño de isolíneas y uso del pre-mapa”. Universidad Nacional de Colombia. Biblioteca Digital. Repositorio Institucional. Disponible:

http://www.bdigital.unal.edu.co/1239/7/06CAPI05.pdf 
BOSQUE SENDRA, J. (1992). Sistemas de Información Geográfica. Ediciones Rialp S.A. Madrid, España.

INSTITUTO GEOGRÁFICO AGUSTín CODAZZI, IGAC (1993). "Principios de Cartografía Temática". Bogotá Colombia, 1993.

JOLY, F. (1979) "La Cartografía". Ediciones Ariel. Barcelona, España.

MADRID SOTO, A. y ORTíz LOPEZ, L. (2005) "Análisis y síntesis en cartografía”. Universidad Nacional de Colombia, Facultad de Ciencias Humanas, Departamento de Geografía

MONKHOUSE, F. y WILKINSON, H. (1966). Mapas y Diagramas. Ediciones Oikos-tau S.A. Barcelona, España.

OJEDA ZUJAR, J. (1999) "La Cartografía Temática: la interpretación frente a la métrica". En Jornadas de Cartografía: La Cartografía hoy: ¿evolución o revolución? Sevilla, España.

ROBINSON, A. (1987). "Elementos de Cartografía" Ediciones Omega. Barcelona, España.

STRAHLER, A. (1973) “Geografía Física”. Ediciones Omega. Barcelona, España.

\section{SITIOS WEB:}

¿Qué es un SIG?. Disponible en http://www.fcagr.unr.edu.ar/mdt/GTS/Zonaedu/GIS7htm.htm Capítulo 4: Mapas de puntos. Disponible en: http://redgeomatica.rediris.es/carto2/pdf/pdfT/tema4t.pdf Cartografía II. Diseño cartográfico: Cartografía Temática. Disponible en: http://redgeomatica.rediris.es/carto2/arbolT/arbolT.htm

Cartografía Temática. Disponible en:

http://www.igac.gov.co:8080/igac_web/UserFiles/File/ciaf/TutorialSIG_2005_26_02/paginas/ctr_cartte matica.htm\#Caracterización\%20de\%20los\%20Mapas\%20Temáticos.

Cartografía Temática. Disponible en:

http://www.igac.gov.co:8080/igac_web/UserFiles/File/ciaf/TutorialSIG_2005_26_02/paginas/ctr_carttem atica.htm

Diseño de Isolíneas y uso del premapa. Disponible

www.digital.unal.edu.co/dspace/bitstream/10245/979/7/06CAPI05.pdf

Enciclopedia GER: Canal Social. Disponible en:

http://www.canalsocial.net/GER/ficha_GER.asp?id=11875\&cat=tecnologia

ICA (Asociación Internacional de Cartografía). Cartografía II: Ficheros. Cartografía temática: Capítulo 1: Introducción a la cartografía temática. Disponible en http://redgeomatica.rediris.es/carto2/pdf/pdfCurso.html

IDE Andalucía: Normativa. Disponible en: http://www.andaluciajunta.es/IDEAndalucia/Normativa.shtml Instituto de Investigación de Recursos Biológicos Alexander von Humboldt Disponible en:http://www.humboldt.org.co/humboldt/mostrarpagina.php?codpage=700071

Instituto Geográfico Nacional. Gobierno de España: Ministerio de Fomento. Disponible en:

http://www.fomento.es/MFOM/LANG_CASTELLANO/DIRECCIONES_GENERALES/INSTITUTO_GE OGRAFICO/ATLAS/CONCEPTOS/SIMBOLI/S\%C3\%ADmb_proporcionales.htm

La cartografía tradicional como ayuda para la selección de los lugares. Disponible en http://www.fao.org/DOCREP/003/T0446S/T0446S06.htm

Mapas de Isolíneas. Disponible en: http://redgeomatica.rediris.es/carto2/pdf/pdfT/tema5t.pdf

Mapas de Isolíneas. Disponible en:

http://www.fomento.es/MFOM/LANG_CASTELLANO/DIRECCIONES_GENERALES/INSTITUTO_GEO GRAFICO/ATLAS/CONCEPTOS/SIMBOLI/isolíneas.htm

Noticias Jurídicas: Base de Datos de Legislación. Disponible en:

http://noticias.juridicas.com/base_datos/Admin/l7-1986.html

Representación cartográfica. Disponible en:

www.geografia.us.es/web/contenidos/becarios/materiales/archivos/representacion_cartografica.pdf

Publicado en formato digital: Prof. Romina Claret, Srta. Carolina Cabrera y Dra. Liliana Ramírez. CARTOGRAFIA TEMÁTICA. Representaciones Cartográficas de Implantación Puntual y Lineal: elaboración mediante Sistemas de Información Geográfica. Revista Geográfica Digital. IGUNNE. Facultad de Humanidades. UNNE. Año 7. № 14. Julio - Diciembre 2010. Resistencia, Chaco. En: http://hum.unne.edu.ar/revistas/geoweb/default.htm 